\title{
MODELING OF DAMAGE PROGRESSION OF RUBBLE MOUND REVETMENT AND APPLICATION TO PERFORMANCE EVALUATION
}

\author{
Takao Ota ${ }^{1}$, Yoshiharu Matsumi ${ }^{2}$, Nobuaki Kato ${ }^{3}$ and Ken-ichi Ohno ${ }^{4}$
}

\begin{abstract}
In this study, the modeling of damage progression of rubble mound revetment and the performance evaluation based on laboratory experiments and numerical computations are performed. The model profiles for the damaged revetment are made on the basis of the experiments to measure the profile change. The model profiles corresponding to the degree of damage are determined by using some empirical equations that are related to the deformation quantity of the revetment. To examine the change of performance due to damage progression, the model profiles are also used in other experiments and numerical computations. The reflection coefficient and overtopping rate are taken as performance indices. The measured reflection coefficient shows a tendency to decrease, while the overtopping rate increases more than twice as much as that of the initial profile with damage progression of the revetment. The computed reflection coefficient and overtopping rate agree reasonably well with the experimental data.
\end{abstract}

Keywords: rubble mound revetment; damage progression; performance evaluation; wave overtopping

\section{INTRODUCTION}

The performance-based design of coastal structures is recently becoming standard. In this design, it is also required to consider the performance retention of structures during the in-service period. Therefore, it is necessary that the relation between the damage of structure and the performance degradation is evaluated to apply the performance-based design. A number of studies about the damage have been conducted for the armor layer of revetment or breakwater based on the hydraulic experiment mainly. For example, Kubota et al. (2009) pointed out that the type of damage depends on the relation between the crest height and incident wave height, however, the relation between the type and degree of damage and the performance of structure has not been made clear sufficiently. In the present study, we perform the modeling of damage progression of rubble mound revetment based on the experimental data of damaged profiles. The purpose is to make average (standard) profiles corresponding to the degree of damage. The model profiles will contribute to the performance evaluation of the damaged revetment through the use of them in laboratory experiments and numerical computations as Ota et al. (2010) mentioned. The reflection coefficient and overtopping rate are taken as performance indices, and laboratory experiments and numerical computations using the model profiles are conducted to investigate the variations of the indices due to the damage progression of the revetment.

\section{EXPERIMENTS TO MEASURE DAMAGED PROFILE}

Laboratory experiments to obtain data of damage progression were conducted in 10 wave flumes that were set up in a multi-directional wave basin (14 m long, $9 \mathrm{~m}$ wide and $0.6 \mathrm{~m}$ high) as shown in Figure 1. The multi-directional wavemaker was the serpent-type and consisted of 14 wave paddles. The wavemaker had no function of wave absorbing. Each wave paddle was driven by servomotors and ball screws at both ends of the paddle. The wave flumes were made by dividing the wavemaker between the paddles by plywood. The plywood was placed through the clearance between the paddles to divide completely including the moving range of paddle.

A conventional rubble mound revetment was constructed on the flat bottom of each wave flume as shown in Figure 2. The crest width was $10 \mathrm{~cm}$ and the heights $h_{c}$ were 5,10 and $15 \mathrm{~cm}$ for the initial profile of the revetment. The seaward slopes of the revetment were 1:1.5 and 1:2. Two types of revetment that were consisted of an armor layer with and without a core were used. For the armor layer, two types of stone whose range of mass, median mass $M_{50}$, mean density $\rho_{s}$ and nominal diameter $D_{n 50}=\sqrt[3]{M_{50} / \rho_{s}}$ were shown in Table 1 were used. The porosity of the armor stone was about 0.41 . The median mass of the gravel that was used for the core was $3.75 \mathrm{~g}$.

The JONSWAP spectrum with the shape parameter $\gamma=3.3$ and the significant wave period $T_{1 / 3}=$ $1.2 \mathrm{~s}$ was used as the target spectrum of the incident irregular wave. The input signal for the wavemaker was computed with the sampling time $\delta t=0.05 \mathrm{~s}$ and number of data $N=32768$. All wave paddles were driven by the signal in the same phase. The waves were generated in a burst of about 27 min and the number of generated waves was approximately 1400 . The waves were generated repeatedly and the total time of wave generation was $189 \mathrm{~min}$ in a test. The significant wave height $H_{1 / 3}$

\footnotetext{
${ }^{1}$ Dept. of Social Systems Eng., Tottori University, 4-101 Koyama Minami, Tottori, 680-8552, Japan

2 Dept. of Social Systems Eng., Tottori University, 4-101 Koyama Minami, Tottori, 680-8552, Japan

${ }^{3}$ Penta-Ocean Construction Co. Ltd., 2-2-8 Koraku, Bunkyo, Tokyo, 112-8576, Japan

${ }^{4}$ Information Media Center, Tottori University, 4-101 Koyama Minami, Tottori, 680-8550, Japan
} 


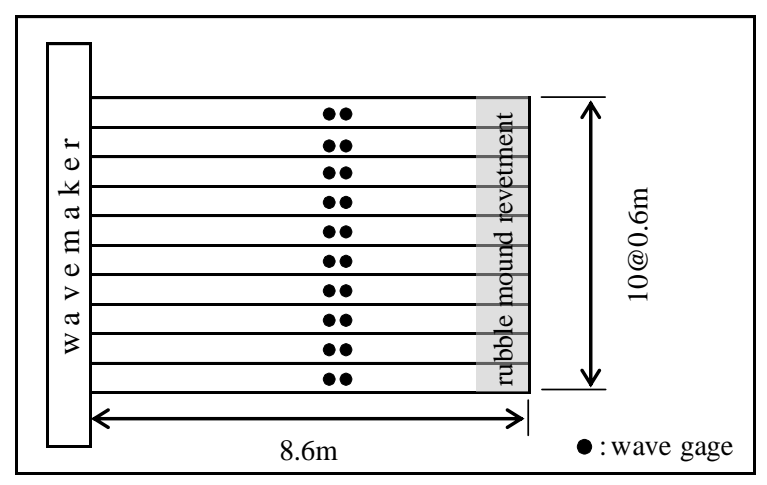

Figure 1. Wave basin and flumes

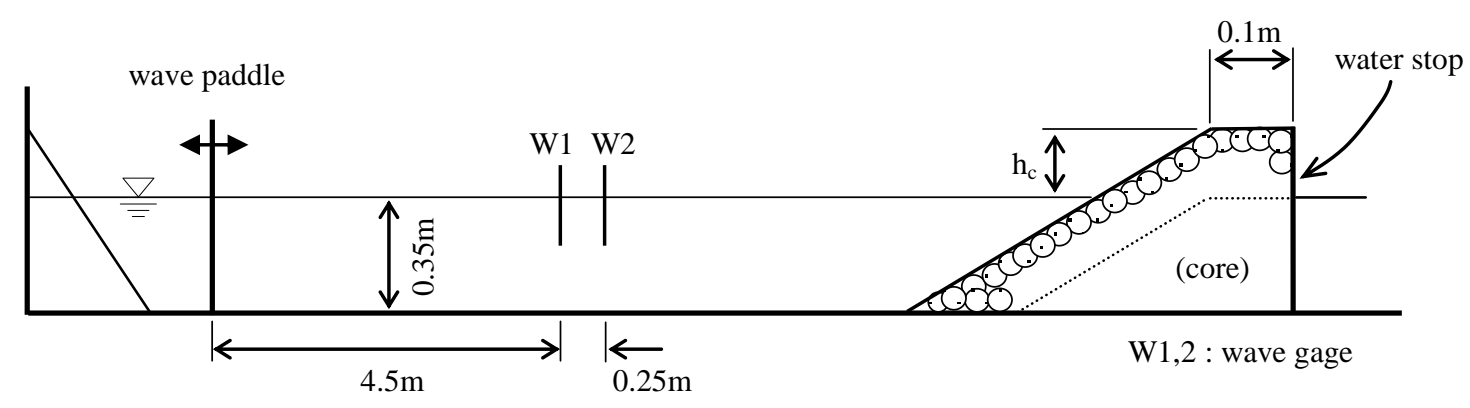

Figure 2. Experimental setup in a wave flume

Table 1. Stone for armor layer

\begin{tabular}{|l|l|}
\hline Range of mass $(\mathrm{g})$ & $50-70,70-100$ \\
\hline$M_{50}(\mathrm{~g})$ & $61.4,88.4$ \\
\hline$\rho_{\mathrm{s}}\left(\mathrm{g} / \mathrm{cm}^{3}\right)$ & $2.76,2.75$ \\
\hline$D_{n 50}(\mathrm{~cm})$ & $2.81,3.18$ \\
\hline
\end{tabular}

was about $11.0 \mathrm{~cm}$ and the stability numbers $N_{s}=H_{1 / 3} /\left(\Delta D_{n 50}\right)$ were 2.0 and 2.2 , where $\Delta=\left(\rho_{s}-\rho_{w}\right) / \rho_{w}$ with $\rho_{w}=$ water density.

The profile of the revetment was measured along cross-shore line using a laser displacement sensor at intervals of $1 \mathrm{~cm}$ horizontally. The output voltage of the sensor was converted into distance for the aerial and submerged parts of the revetment separately. The conversion factors were obtained using square columns set in the air and water. In the measurement of profile, it was confirmed that there was no gap in the measured profile at the boundary between the aerial and submerged parts. The profiles of the revetment were measured along three cross-shore lines in each wave flume every 27 min of irregular wave action. The profile of the revetment was given as the average of the profiles along three lines. The normalized eroded area $S=A_{e} / D_{n 50}^{2}$ with $A_{e}=$ eroded area was used as a parameter that showed the deformation quantity of the revetment. The number of tests under the same conditions of the revetment was four and a total of 80 tests were conducted.

\section{MODELING OF DAMAGE PROGRESSION}

Figure 3 shows the measured profile evolution of the revetment in the case of the relatively heavy damage in the experiments. The number in the parenthesis indicates the value of $S$ for each profile. The profile of the eroded part became linear with the damage progression as Kajima et al. (1993) and Kubota et al. (2009) showed. As the result, the relatively heavy damage in the crest and slope of the revetment occurred in the cases of 1:1.5 slope and $h_{c}=10 \mathrm{~cm}$ with core. Hereafter, the cases of $D_{n 50}=$ $2.81 \mathrm{~cm}$ and $3.18 \mathrm{~cm}$ are expressed as Case 1 and Case 2 respectively. The modeling of damaged profile is conducted for these cases using the experimental data because Ota et al. (2010) already proposed a method to make model profile in the case of damage occurred in the slope of revetment. 


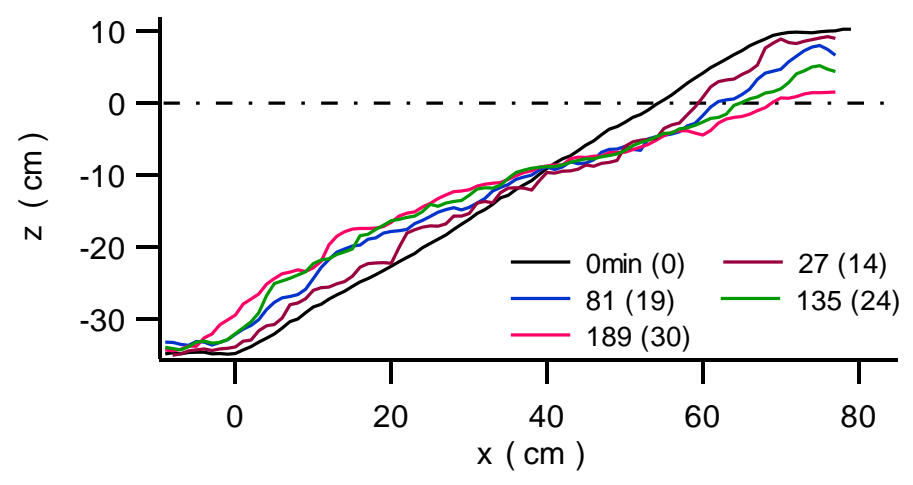

(a) $D_{n 50}=2.81 \mathrm{~cm}, N_{s}=2.2$, Test 1_1

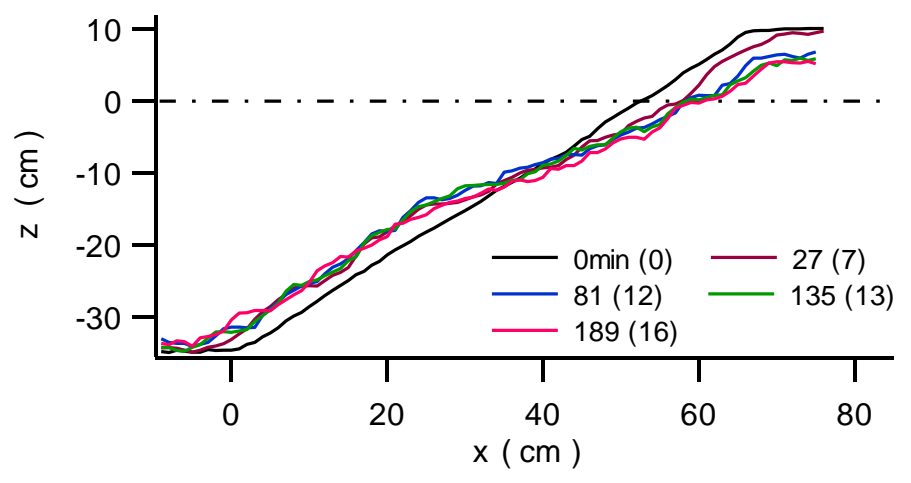

(b) $D_{n 50}=3.18 \mathrm{~cm}, \mathrm{~N}_{\mathrm{s}}=2.0$, Test 2_3

Figure 3. Measured profile evolution

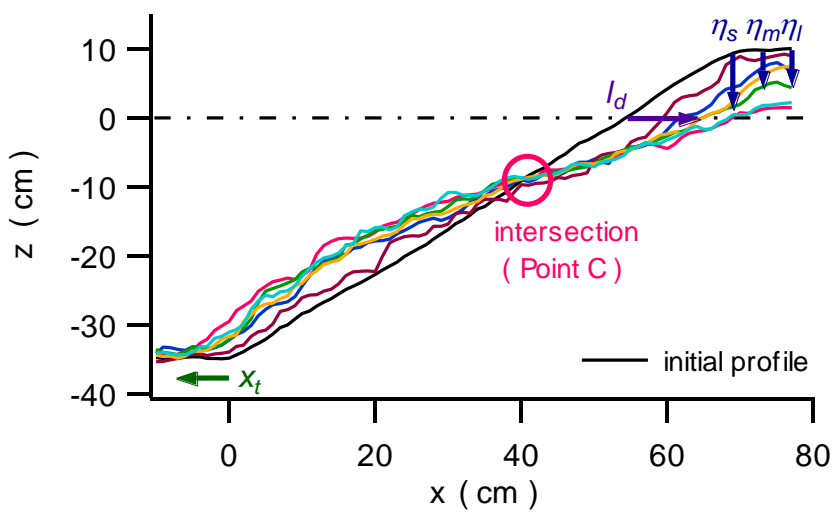

Figure 4. Quantities used for model profile

The damage occurred in the slope of revetment only or the slight deformation of the revetment was observed in the other cases of the experiment. The model profiles corresponding to $S$ are made using the intersections between the initial profile and damaged profiles (Point $\mathrm{C}$ ), the decrements of crest height $\eta$ at three points of the crest, the horizontal decrement of the armor layer at still water level $l_{d}$ and the horizontal displacement of the toe $x_{t}$, which are shown in Figure 4 schematically.

Because the positions of the intersections don't change much in spite of the damage progression, the coordinate of Point $\mathrm{C}$ is given by the average of obtained $\mathrm{x}$-coordinates $\overline{x_{C}}$ and the corresponding $\mathrm{z}$ coordinate on the initial profile $\overline{z_{C}}$. As the result, the positions of Point $\mathrm{C}$ are $\overline{x_{C}}=37.2 \mathrm{~cm}, \overline{z_{C}}=-10.2$ $\mathrm{cm}$ for Case 1 and $\overline{x_{C}}=36.3 \mathrm{~cm}, \overline{z_{C}}=-10.8 \mathrm{~cm}$ for Case 2. The values of $\eta$ and $x_{t}$ are given by the empirical equations based on the experimental data. Figures 5 and 6 show the relation between $S$ and $\eta$ at the seaward edge, the middle and the landward edge of the crest that are represented by $\eta_{s}, \eta_{m}$ and $\eta_{l}$ 
respectively. The regression curves and formulas obtained by the method of least squares are also shown in the figures. The decrements $\eta_{s}, \eta_{m}$ and $\eta_{l}$ for the model profile are given by the empirical equations corresponding to the value of $S$. The model profile for the eroded part is determined by using $\eta_{s}, \eta_{m}, \eta_{l}$, Point $\mathrm{C}$ and $l_{d}$ and connecting the five points by straight line. The relation between $l_{d}$ and $S$ can be also obtained in the same manner as $\eta$. However, the value of $l_{d}$ is determined so that the area surrounded by the initial and model profiles is equal to the eroded area $A_{e}=S D_{n 50}^{2}$.

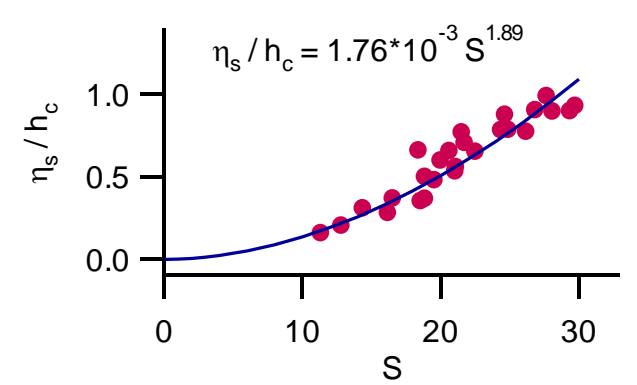

(a) $\eta_{s} / h_{c}$

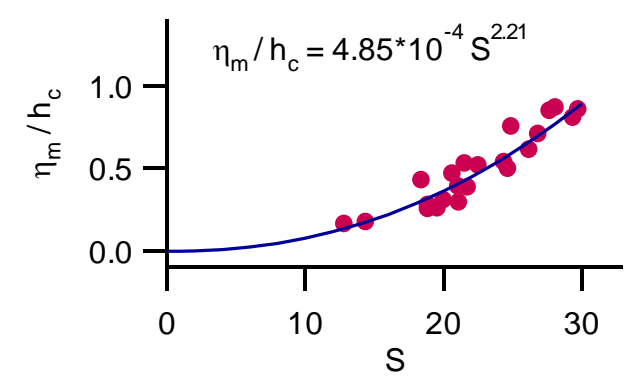

(b) $\eta_{m} / \mathbf{h}_{\mathrm{c}}$

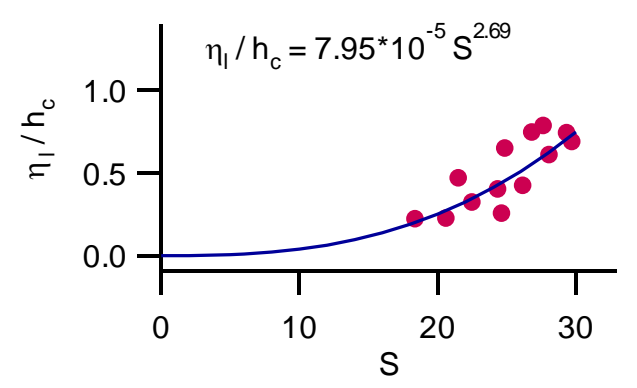

(c) $\eta_{1} / \mathbf{h}_{\mathrm{c}}$

Figure 5. Relation between $\eta$ and S (Case 1)

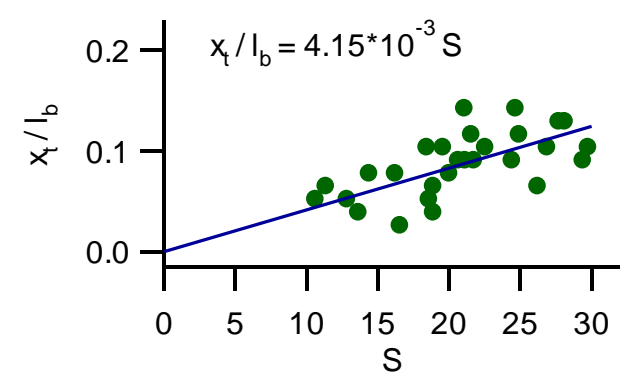

(a) Case 1

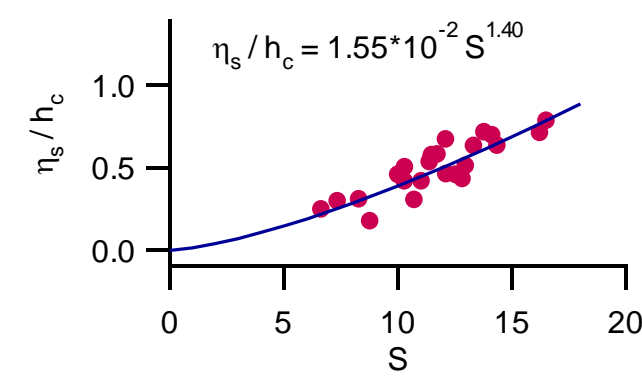

(a) $\eta_{s} / h_{c}$

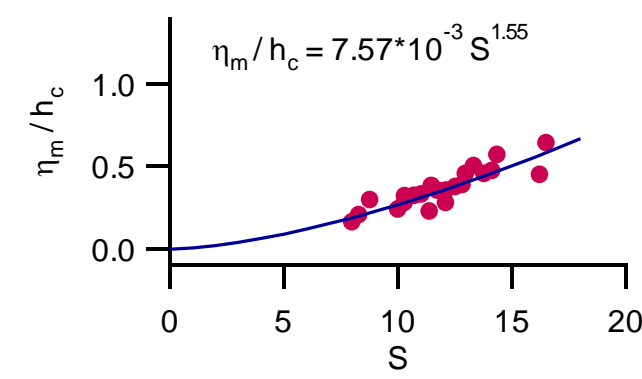

(b) $\eta_{m} / h_{c}$

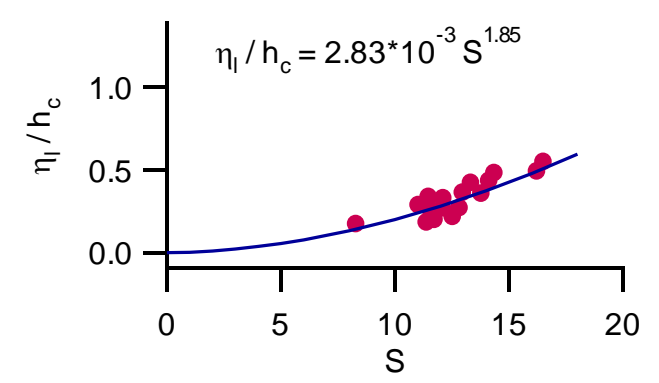

(c) $\eta_{1} / h_{c}$

Figure 6. Relation between $\eta$ and S (Case 2)

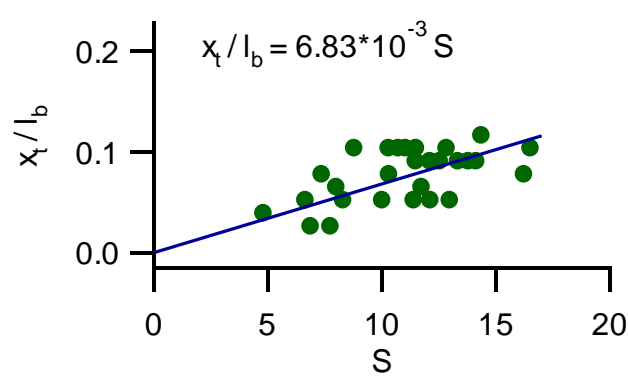

(b) Case 2

Figure 7. Relation between $x_{t}$ and $S$ 


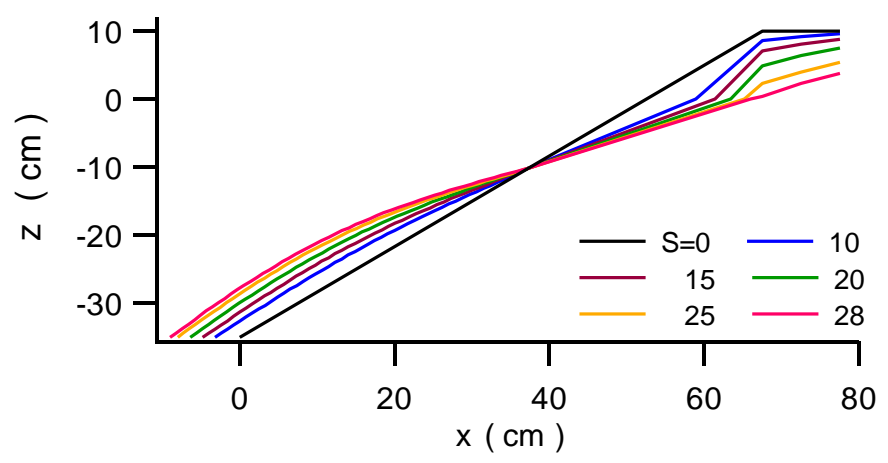

(a) Case 1

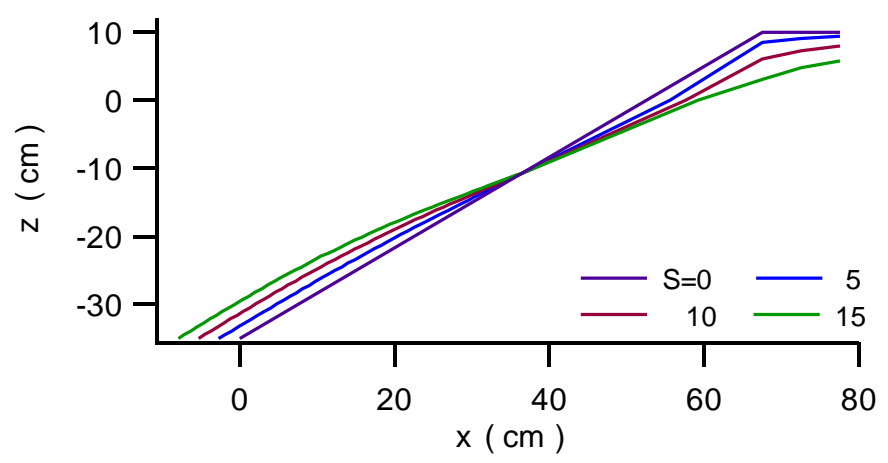

(b) Case 2

Figure 8. Model profiles

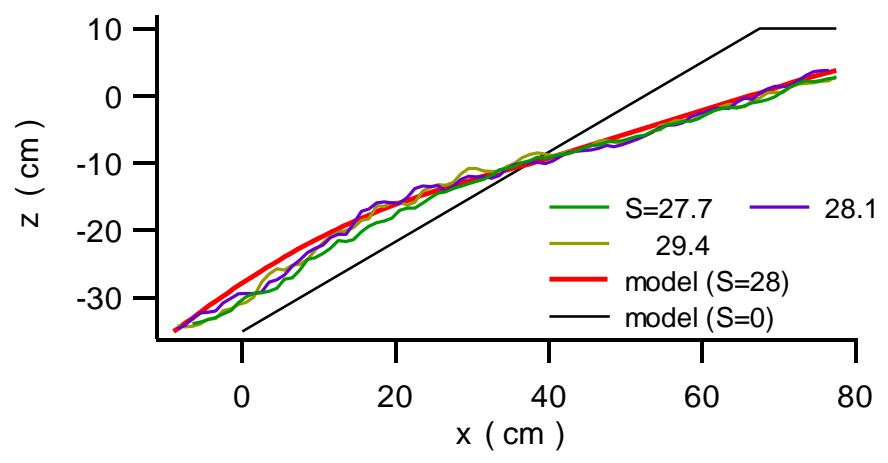

(a) Case 1 (S $\approx 28)$

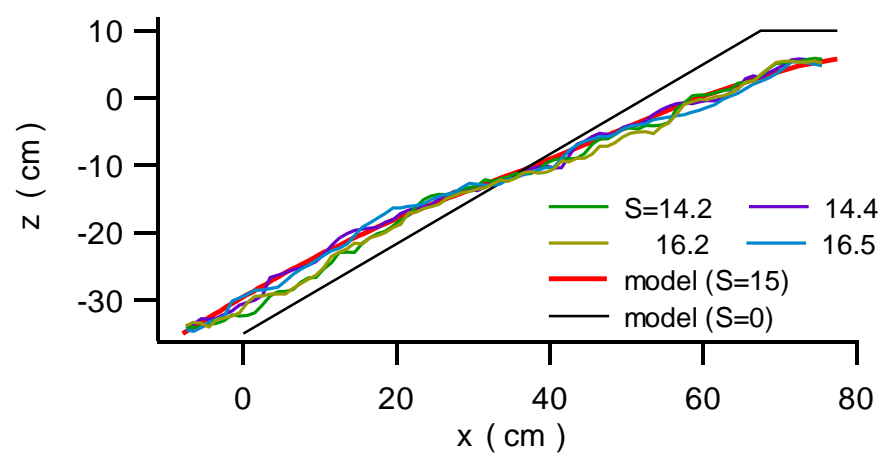

(b) Case $2(S \approx 15)$

Figure 9. Comparisons of model profiles with experimental data 
Figure 7 shows the relation between the normalized displacement of the toe $x_{t} / l_{b}$ and $S$, where $l_{b}=$ initial length of the base of revetment. The value of $x_{t}$ corresponding to $S$ is given by the regression formula shown in Figure 7. In the same way as Ota et al. (2010), the model profile for the accumulated part is given by a sine curve whose wave length is twice of the distance between the toe and Point C. The wave amplitude is determined so as to make the accumulated area equal to the eroded area corresponding to $S$.

The model profiles in the case of $S=0$ (initial profile), 10, 15, 20, 25 and 28 for Case 1 , and $S=0$, 5, 10 and 15 for Case 2 are shown in Figure 8. Figure 9 compares the model profile in the case of $S=$ 28 for Case 1 and $S=15$ for Case 2 with the measured profiles whose values of $S$ are nearly equal in Case 1 and 2. The model profiles agree well with the experimental data.

\section{PERFORMANCE EVALUATION}

Laboratory experiments and numerical computations are conducted to evaluate the performance of the damaged rubble mound revetment. The revetments that have the model profiles corresponding to $S$ $=0,10,15,20,25$ and 28 for Case 1 , and $S=0,5,10$ and 15 for Case 2 are used in the experiments and computations. The reflection coefficient and overtopping rate are taken as performance indices.

The experiments were conducted in a wave flume that was $29 \mathrm{~m}$ long, $0.5 \mathrm{~m}$ wide and $0.75 \mathrm{~m}$ high. The wavemaker had the function of wave absorbing and it was used in the experiments. The revetment that had the model profile was set on the flat bottom of the flume. The experimental setup is shown in Figure 10 and the revetment in this figure has the initial profile. The crest and seaward slope of the revetment was covered by a wire sheet to fix the armor stone. The gravel that was used for the core passed the sieve of $4.76 \mathrm{~mm}$ and remained on that of $9.50 \mathrm{~mm}$. The porosity of the gravel was about 0.37 .

The regular and irregular waves were generated to obtain the reflection coefficient. Five wave gages were placed to measure the time series of the free surface elevation. Wave gages W1-W3 were used to separate the incident and reflected waves using linear wave theory. The regular waves with wave period $T=0.8,1.0,1.2,1.4,1.6,1.8,2.0 \mathrm{~s}$ and wave height $H=6 \mathrm{~cm}$ were used as the incident waves. The regular waves were generated in bursts of $100 \mathrm{~s}$. Moreover, the irregular waves whose target spectrum was the modified Bretschneider-Mitsuyasu spectrum with $T_{1 / 3}=1.6 \mathrm{~s}$ and $H_{1 / 3}=6 \mathrm{~cm}$ was generated as the incident wave in a burst of 10 min.

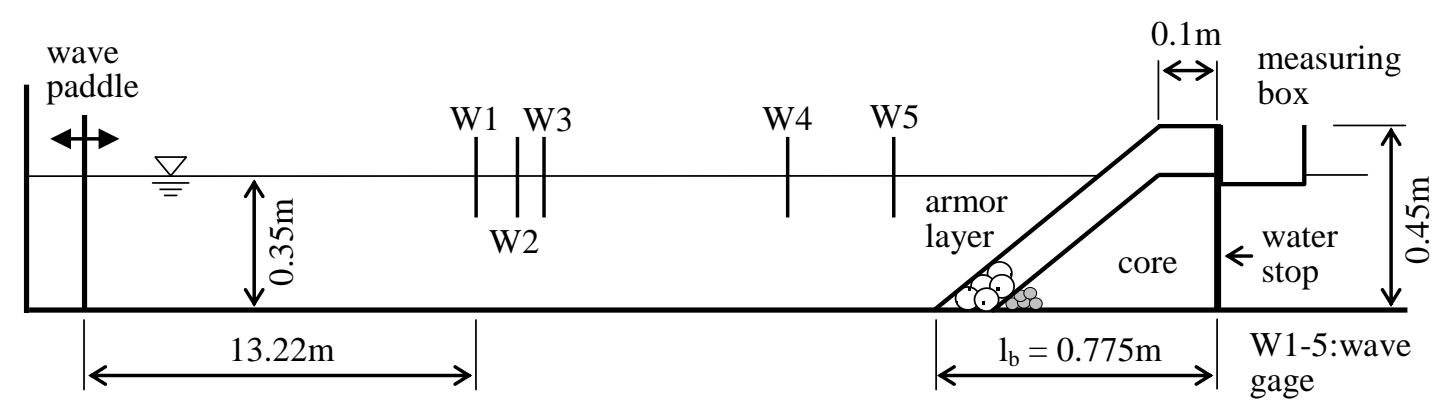

Figure 10. Experimental setup to measure performance indices

Table 2. Conditions and values of parameters for CADMAS-SURF

\begin{tabular}{|l|l|l|}
\hline \multicolumn{2}{|c|}{ analysis time $(\mathrm{s})$} & 300 \\
\hline \multicolumn{2}{|c|}{ wave model } & wave source \\
\hline \multicolumn{2}{|c|}{ difference scheme } & VP-DONOR 0.2 \\
\hline \multirow{2}{*}{ grid interval $(\mathrm{cm})$} & vertical & 1.0 \\
\cline { 2 - 3 } & horizontal & $2.0\left(1.0^{\star}\right)$ \\
\hline \multirow{4}{*}{ armor layer } & porosity & 0.41 \\
\cline { 2 - 3 } & inertia coefficient & 1.2 \\
\cline { 2 - 3 } core & drag coefficient & 1.0 \\
\hline & porosity & 0.37 \\
\cline { 2 - 3 } & inertia coefficient & 2.0 \\
\cline { 2 - 3 } & drag coefficient & 1.5 \\
\hline
\end{tabular}


The modified Bretschneider-Mitsuyasu spectrum with $T_{1 / 3}=1.6 \mathrm{~s}$ and $H_{1 / 3}=10.3 \mathrm{~cm}$ was used as the target spectrum of the incident irregular wave for the measurement of overtopping quantity. The wave was generated in a burst of $20 \mathrm{~min}$ and the significant wave height of the generated incident wave was about $10.0 \mathrm{~cm}$. A measuring box whose width was $37.5 \mathrm{~cm}$ was placed behind the water stop to collect the overtopped water as shown in Figure 10. The irregular wave was generated twice for each model profile of the revetment and the overtopping quantity was given as the average. The reflection coefficient was also obtained in this experiment.

In this study, a two-dimensional numerical wave flume "CADMAS-SURF" (Coastal Development Institute of Technology, 2001, 2008) V5.1 is also used to predict the reflection coefficient and overtopping rate. The governing equations are the continuity equation and Navier-Stokes equation for incompressible and viscous fluid. The water surface variation is computed using the volume of fluid (VOF) method. A water stop and measuring box are set behind the revetment and the volume of overtopped water is computed from the increment of the VOF function F in the box. The water depth in the flume, the location of wave gages and the location and profile of the revetment are same as the experiments described above. The reflection coefficient is estimated using the three-gages method in the same way as the experiment. The modified Bretschneider-Mitsuyasu spectrum is used as the given target spectrum of the incident irregular wave. The input conditions for the wave are $T_{1 / 3}=1.6 \mathrm{~s}$ and $H_{1 / 3}=11.5 \mathrm{~cm}$. The input value of $H_{1 / 3}$ is determined by the result of the calibration calculation without the revetment and $H_{1 / 3}$ is about $10.0 \mathrm{~cm}$ for the computed irregular wave. The other conditions and values of parameters are as shown in Table 2.

Figure 11 shows the variations of the reflection coefficient $K_{R}$ obtained from the experiments using the model profiles. The measured $K_{R}$ shows a tendency to decrease with increasing $S$ except for the cases of $T=1.2 \mathrm{~s}$ in Case 1 and $T=1.0,1.2 \mathrm{~s}$ in Case 2 . The variations of $K_{R}$ were in the range of 0.02 - 0.23 in Case 1 and $0.04-0.23$ in Case 2 . In the cases of $T=1.6,1.8 \mathrm{~s}$ in Case $1, K_{R}$ increased slightly in the region of large $S$.

Table 3 and Figure 12 show the comparisons of the measured $K_{R}$ and overtopping rate $q_{o}$ with the predicted values of them. The measured $K_{R}$ was obtained from the experiment for the measurement of

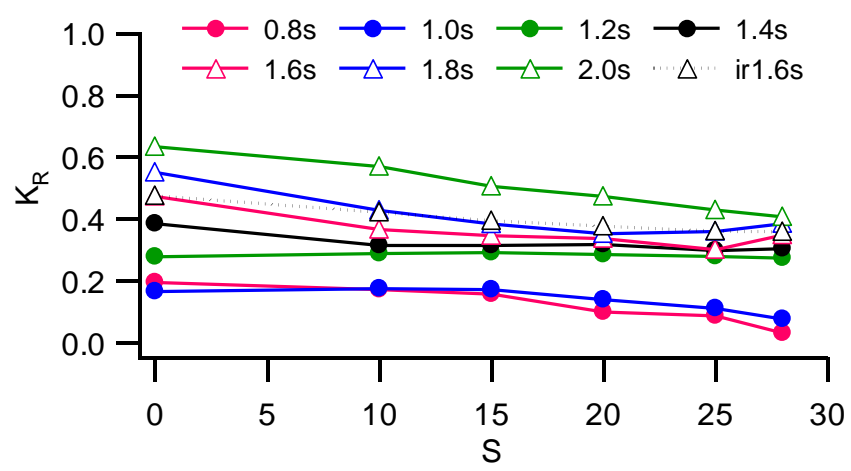

(a) Case 1

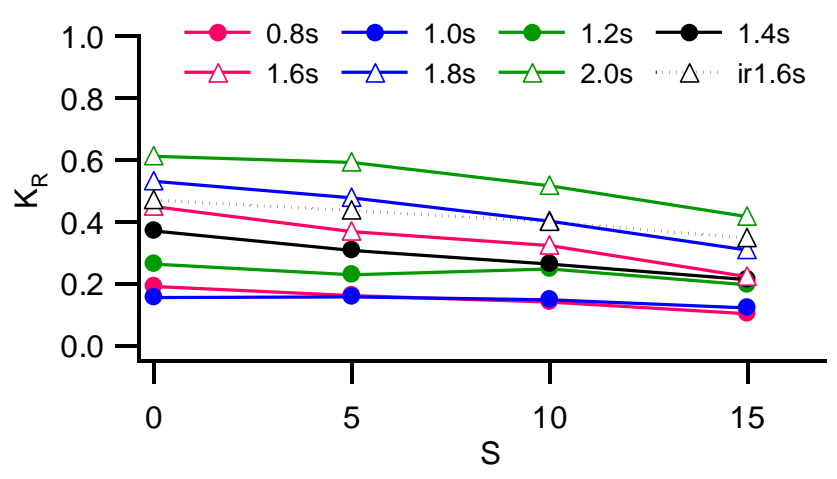

(b) Case 2

Figure 11. Variations of measured $K_{R}$ 
Table 3. Comparisons of measured $K_{R}$ and $q_{0}$ with predicted values

(a) Case 1

\begin{tabular}{|c|c|c|c|c|c|c|c|c|c|c|c|c|}
\hline \multirow{2}{*}{} & \multicolumn{2}{|c|}{$\mathrm{S}=0$} & \multicolumn{2}{c|}{$\mathrm{S}=10$} & \multicolumn{2}{c|}{$\mathrm{S}=15$} & \multicolumn{2}{c|}{$\mathrm{S}=20$} & \multicolumn{2}{c|}{$\mathrm{S}=25$} & \multicolumn{2}{c|}{$\mathrm{S}=28$} \\
\cline { 2 - 14 } & meas. & pred. & meas. & pred. & meas. & pred. & meas. & pred. & meas. & pred. & meas. & pred. \\
\hline $\mathrm{K}_{\mathrm{R}}$ & 0.49 & 0.44 & 0.44 & 0.42 & 0.41 & 0.40 & 0.40 & 0.40 & 0.39 & 0.41 & 0.38 & 0.40 \\
\hline $\mathrm{q}_{\mathrm{o}}\left(\mathrm{cm}^{2} / \mathrm{s}\right)$ & 1.04 & 1.21 & 1.73 & 1.98 & 2.23 & 2.52 & 2.72 & 3.04 & 2.29 & 2.82 & 1.99 & 2.78 \\
\hline
\end{tabular}

(b) Case 2

\begin{tabular}{|c|c|c|c|c|c|c|c|c|}
\hline & \multicolumn{2}{|c|}{$\mathrm{S}=0$} & \multicolumn{2}{c|}{$\mathrm{S}=5$} & \multicolumn{2}{c|}{$\mathrm{S}=10$} & \multicolumn{2}{c|}{$\mathrm{S}=15$} \\
\cline { 2 - 9 } & meas. & pred. & meas. & pred. & meas. & pred. & meas. & pred. \\
\hline $\mathrm{K}_{\mathrm{R}}$ & 0.48 & 0.45 & 0.44 & 0.43 & 0.41 & 0.40 & 0.36 & 0.39 \\
\hline $\mathrm{q}_{\mathrm{o}}\left(\mathrm{cm}^{2} / \mathrm{s}\right)$ & 0.86 & 1.21 & 1.36 & 2.02 & 1.63 & 2.64 & 1.85 & 2.49 \\
\hline
\end{tabular}

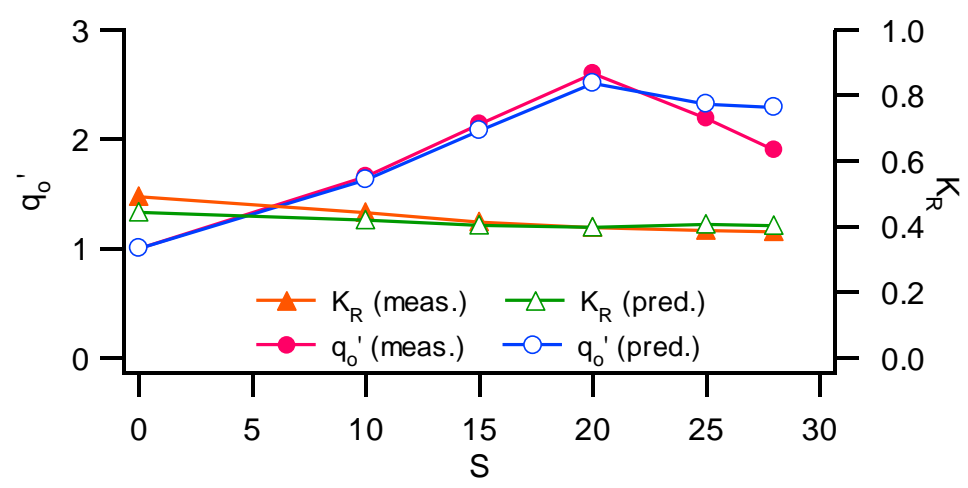

(a) Case 1

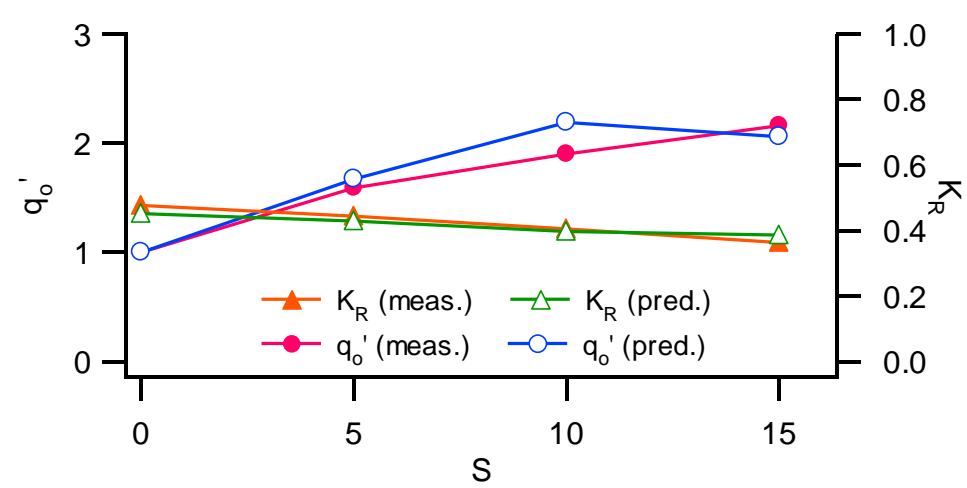

(b) Case 2

Figure 12. Comparisons of measured $K_{R}$ and $q_{0}{ }^{\prime}$ with predicted values

overtopping quantity. The left vertical axis $q_{o}{ }^{\prime}$ in Figure 12 means the overtopping rate normalized by that of the initial profile. The predicted $K_{R}$ agrees well with the measured. The maxima of $q_{o}{ }^{\prime}$ are about 2.6 in Case 1 and 2.2 in Case 2 in both the measured and predicted. The numerical model predicts $q_{o}$ within about $40 \%$ error and the variation with $S$ agrees with the data. It is conceivable that the exposed water stop and gentle slope of the damaged revetment influence the decrease of $q_{o}$ in the region of $S>$ 20 in Case 1.

\section{CONCLUSIONS}

A series of laboratory experiments were conducted in ten wave flumes to investigate the profile change due to damage progression of the rubble mound revetments under some conditions. Based on 
the experimental data, the model profiles corresponding to the degree of damage progression are made for the cases of relatively heavy damage including the crest of the revetment. Furthermore, laboratory experiments and numerical computations using the model profiles are conducted to evaluate the performance of the damaged revetment. The reflection coefficient and overtopping rate are taken as performance indices. The conclusions of this study are summarized as follows;

1. The model profiles corresponding to the normalized eroded area $S$ are obtained by using some empirical equations based on the experimental results and a sine curve. The model profiles agree well with the measured profiles.

2. The measured reflection coefficient $K_{R}$ obtained from the experiments using the model profiles shows a tendency to decrease with increasing $S$.

3. The ratios of overtopping rate $q_{o}$ in the initial profile to the maximum are about 2.6 for Case $1\left(D_{n 50}\right.$ $=2.81 \mathrm{~cm})$ and 2.2 for Case $2\left(D_{n 50}=3.18 \mathrm{~cm}\right)$ in both the measured and predicted results.

4. The numerical model predicts $q_{o}$ within about $40 \%$ error and the variation with $S$ agrees with the experimental data.

\section{ACKNOWLEDGMENTS}

The authors express our gratitude to Katsuya Imamura, Hiromichi Yoshiki and Kosuke Hirata for their contributions to the experiments.

\section{REFERENCES}

Coastal Development Institute of Technology. 2001. CADMAS-SURF; Its research and development, 296pp. (in Japanese)

Coastal Development Institute of Technology. 2008. CADMAS-SURF; Examples of practical calculation, 306pp. (in Japanese)

Kajima, R., T. Sakakiyama, M. Matsuyama, T. Sekimoto and O. Kyoya. 1993. Stability of armor layer of man-made island sea-wall and overtopping due to extremely large irregular waves, Proceedings of 40th Japanese Conference on Coastal Engineering, JSCE, 686-690. (in Japanese)

Kubota, S., M. Yamamoto, A. Matsumoto and M. Hanzawa. 2009. An experimental study on deformation of wave-dissipating concrete blocks covering caisson breakwaters, Journal of Coastal Engineering, JSCE, Vol. 56, 906-910. (in Japanese)

Ota, T., Y. Matsumi, T. Hirayama and A. Kimura. 2010. Proceedings of the International Conference on Coastal Engineering, No. 32(2010), Paper \#: structures.38. Retrieved from http://journals.tdl.org/ICCE/ 